\title{
GÂY MÊ CHO BẸNH NHÂN CÓ HỘI CHỨNG BRUGADA
}

\author{
Phạm Quang Minh'1, ${ }^{1}$, Vũ Hoàng Phương1', Lưu Quang Thuỳ ${ }^{2}$
}

${ }^{1}$ Trường Đại học Y Hà Nội

²Bệnh viện Việt Đức

Hội chứng Brugada là một tình trạng liên quan đến bất thường kênh Natri ở tim trên quả tim có cấu trúc bình thường. Chẩn đoán bệnh dựa vào đặc điểm trên điện tâm đồ cộng với biểu hiện lâm sàng và/hoặc xét nghiệm gen. Bệnh nhân được chẩn đoán hội chứng Brugada có thể bị đột tử do rối loạn nhịp thất mà không có tiền triệu, vì vậy nếu phải gây mê để phẫu thuật thì nguy cơ rủi ro là rất cao. Bác sỹ gây mê cần hiểu rõ cơ chế bệnh sinh của bệnh, các yếu tố thuận lợi xuất hiện loạn nhịp, những thuốc có thể gây khởi phát loạn nhịp. Qua đó có thể lựa chọn phương pháp vô cảm đúng, các thuốc gây mê phù hợp để đảm bảo an toàn tối đa cho bệnh nhân này. Trên cơ sở xem lại một loạt báo cáo ca lâm sàng cộng với nghiên cứu y văn thì giải pháp cho bệnh nhân là: chuẩn bị săn sàng máy khử rung ngoài, kiểm soát yếu tố nguy cơ, duy trì mê bằng thuốc mê bốc hơ', không truyền Propofol liên tục.

Từ khóa: Hội chứng Brugada, loạn nhịp thất, gây mê cho bệnh nhân có loạn nhịp tim.

\section{I. ĐĂT VẤN ĐỀ}

Ngay sau sự kiện cầu thủ người Đan Mạch Eriksen bị đột quỵ khi đang thi đấu. Các bác sỹ tim mạch đã hội chẩn và rút ra kết luận cầu thủ này có mang gen đột biến gây hội chứng Brugada. Hội chứng Brugada là một bệnh lý hiếm gặp liên quan đến bất thường kênh ion ở tim, trên bệnh nhân có cấu trúc quả tim bình thường, bệnh nhân có nguy cơ loạn nhịp thất và tử vong. ${ }^{1}$ Hội chứng này lần đầu tiên được mô tả năm 1992, bởi anh em nhà Brugada người Bỉ bao gồm Block nhánh phải, ST chênh lên kéo dài, đột tử. ${ }^{2}$ Theo thống kê hội chứng này là nguyên nhân của $4 \%$ các đột tử và trên $20 \%$ các đột tử do nguyên nhân tim mạch ở bệnh nhân không có rối loạn về cấu trúc cơ tim. ${ }^{3}$ Những bệnh nhân có hội chứng này kể cả đã biết trước hoặc tiềm ẩn đều có thể phải trải qua cuộc mổ bất cứ lúc nào. Kỹ thuật gây mê

Tác giả liên hệ: Phạm Quang Minh

Trường Đại học Y Hà Nội

Email: phamquangminh@hmu.edu.vn

Ngày nhận: 11/08/2021

Ngày được chấp nhận: 26/08/2021 hồi sức, các thuốc dùng trong gây mê hồi sức mặc dù có rất nhiều tiến bộ nhưng tỷ lệ tai biến liên quan đến gây mê hồi sức vẫn còn cao, nhất là trên bệnh nhân có bệnh nền nặng. ${ }^{4}$ Các bác sỹ gây mê thường e ngại khi đối mặt với bệnh nhân có bệnh tim mạch đặc biệt là các rối loạn nhịp như hội chứng Brugada. Các thuốc dùng trong gây mê ảnh hưởng nhiều đến khoảng ST, đến dẫn truyền cơ tim và có thể khởi phát các rối loạn nhịp nguy hiểm trên bệnh nhân có bệnh tim từ trước. ${ }^{5}$ Trên cơ sở tìm hiểu sinh lý bệnh của hội chứng Brugada, các thuốc dùng trong gây mê có thể khởi phát loạn nhịp, các giai đoạn phẫu thuật có thể xuất hiện loạn nhip. Chúng tôi muốn trình bày các chiến lược nên được áp dụng khi người bệnh có hội chứng Brugada cần phẫu thuật, với mục tiêu bảo đảm an toàn tối đa cho họ cả trước trong và sau phẫu thuật.

\section{NỌI DUNG TỎNG QUAN}

\section{1. Đặc điểm lâm sàng và cận lâm sàng}

\section{Lâm sàng}

Các triệu chứng thường xuất hiện ở người lớn tuổi từ 40 - 45, mặc dù y văn đã ghi nhận 
có những bệnh nhân từ 2 ngày tuổi đến 84 tuổi. Bệnh có liên quan đến vị trí địa lý, hay gặp ở Châu Á đặc biệt là Đông Nam Á hơn so với Châu Âu. Tỷ lệ ở Châu Âu là 1 - 5/10000 người, trong khi ở Đông Nam Á tỷ lệ lên tới 12/10000 người. ${ }^{6}$ Phần lớn bệnh nhân có tiền sử gia đình có người đột quỵ hay rối loạn nhịp tim ác tính. Hội chứng Brugada có 3 thể lâm sàng như sau:

\section{Thể có triệu chứng}

Triệu chứng thường gặp nhất là ngất hoặc đột tử, thường xẩy ra vào ban đêm do rối loạn nhịp thất.

\section{Thể không có triệu chứng}

Điện tâm đồ có đặc trưng của hội chứng Brugada nhưng bệnh nhân không có biểu hiện lâm sàng.

\section{Thể ẩn}

Bệnh nhân mang đột biến gen nhưng không có biểu hiện lâm sàng và điện tâm đồ ngay cả khi test bằng thuốc chống loạn nhịp.

\section{Đặc điểm trên điện tâm đồ, đặc điểm về di truyền}

Điện tâm đồ của hội chứng Brugada thay đổi, thường có ST chênh lên ở các chuyển đạo trước tim phải. Các đặc điểm trên điện tâm đồ có thể chuyển sang dạng giả bình thường. Mất tri giác hoặc đột tử có thể xuất hiện mà không có tiền triệu tất cả đều là nguyên nhân của nhịp nhanh thất hoặc rung thất.

Ba hình ảnh trên điện tâm đồ đã được phân loại, qua đó có ba type hội chứng Brugada như sau: ${ }^{7}$

\begin{tabular}{lccc}
\hline \multicolumn{1}{c}{ Thông số } & Type 1 & Type 2 & Type 3 \\
\hline Biên độ sóng J & $\geq 2 \mathrm{~mm}$ & $\geq 2 \mathrm{~mm}$ & $\geq 2 \mathrm{~mm}$ \\
\hline Sóng T & Âm & Dương hoặc 2 pha & Dương \\
\hline Hình dạng ST - T & Dạng vòm & Dạng yên ngựa & Dạng yên ngựa \\
\hline Đoạn ST (phần cuối) & Dốc xuống dần & Chênh lên $\geq 1 \mathrm{~mm}$ & Chênh lên $\leq 1 \mathrm{~mm}$ \\
\hline
\end{tabular}
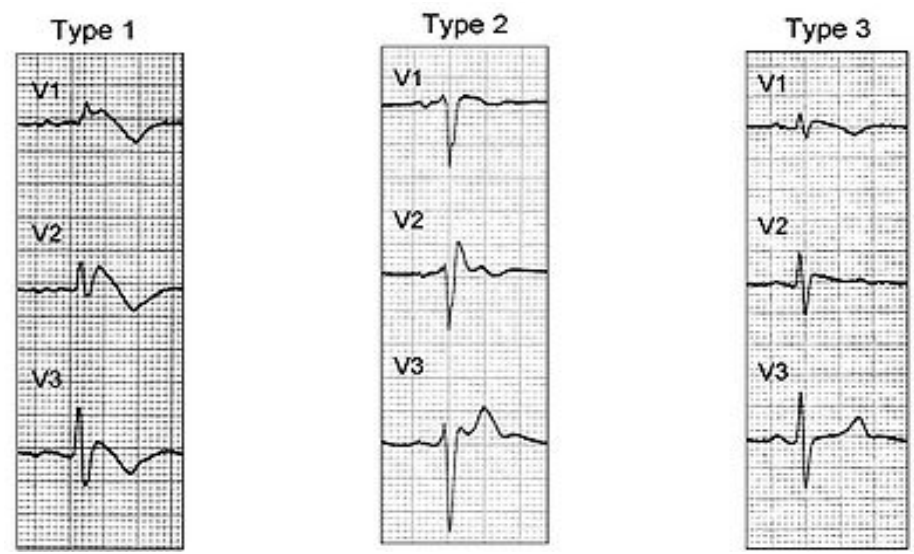

Hình 1. Điện tâm đồ của hội chứng Brugada

Điện tâm đồ của hội chứng Brugada thường bị che dấu, tuy nhiên một số yếu tố gây biểu hiện như sau: ${ }^{7}$

- Chất ức chế kênh Natri

- Sốt

- Chất cường phó giao cảm 
- Chất cường $\mu$ giao cảm

- Thuốc chẹn b

- Thuốc chống trầm cảm 3 vòng

- Thuốc kháng Histamin thế hệ 1

- Hỗn hợp glucose và insulin

- Tăng Kali, giảm Kali, tăng Calci

- Ngộ độc rượu, ngộ độc cocain...

Liên quan đến thuốc, các nhà tim mạch đã lập một trang web chỉ ra chi tiết các thuốc được phép dùng, các thuốc cân nhắc khi dùng và các thuốc không được phép dùng. Trang web là có địa chỉ là http://www.Brugadadrugs.org, được thành lập ngày 24/01/2015 và update tháng12/2020.

\section{Đặc điểm di truyền}

Hiện nay đã xác định được 10 đột biến gen gây hội chứng Brugada, phổ biến nhất là đột biến gen $\mathrm{SCN} 5 \mathrm{~A}$ nằm trên nhiễm sắc thể số 3 , tính trội. Đây là đột biến gen mã hoá tiểu đơn vị $\mu$ của kênh Natri ở tim. Đột biến này làm giảm mức độ bộc lộ kênh Natri, làm giảm dòng ion Natri, gia tăng sự bất hoạt kênh Natri. Tuy nhiên, mối liên hệ giữa các bất thường này đến sự chênh lên của đoạn ST còn chưa được hiểu một cách đầy đủ. Mặc dù các kiểu đột biến gen của hội chứng Brugada xuất hiện trên cả hai giới nhưng kiểu hình có xu hướng nặng hơn nhiều ở nam.

\section{Chẩn đoán}

Hội chứng Brugada còn chưa được định nghĩa rõ nên việc chẩn đoán xác định là khó. Hai đặc điểm bao gồm điện tim và lâm sàng là quan trọng để chẩn đoán bệnh.

Thể có triệu chứng (Type 1) được chẩn đoán dựa vào tiêu chuẩn của Hội Tim mạch Châu Âu. Xuất hiện ST chênh lên typ 1 ở nhiều hơn một chuyển đạo trước tim phải (V1 - V3), có hoặc không có thuốc chẹn kênh natri, cộng với ít nhất một trong những biểu hiện sau:

- Rung thất đã được chứng minh bằng khai thác tiền sử.

- Nhịp nhanh thất đa hình tự ngừng.
- Tiền sử gia đình của đột tử do tim ở tuổi $<45$ tuổi.

- Chênh lên của đoạn ST type 1 ở các thành viên trong gia đình.

- Khả năng tạo ra nhịp nhanh thất bằng điện sinh lý.

- Nghi ngờ nhịp nhanh gây ra ngất không giải thích được.

- Thở hấp hối (agonal) về ban đêm.

Thể không có triệu chứng, thể ẩn (Type 2 và Type 3) được chẩn đoán dựa vào sự xuất hiện ST chênh lên type 2, type 3 ở nhiều hơn 1 chuyển đạo bên ngực phải, có sự đảo ngược thành ST chênh lên type 1 sau khi dùng thuốc chẹn kênh natri. Một trong những đặc điểm lâm sàng được mô tả ở trên $(\mathrm{a}-\mathrm{g})$, cộng với sự đảo ngược của type 3 thành type 2 của đoạn ST bằng thuốc không đủ để chẩn đoán.

Không phải tất cả bệnh nhân có hình ảnh điện tâm đồ của hội chứng Brugada type 2 hay type 3 đều cần phải test bằng thuốc, nhất là khi các bệnh nhân đã được chứng minh qua khai thác tiền sử có đặc điểm lâm sàng $a, b, f$ và $g$. Đa số các bệnh nhân như vậy sẽ được đặt máy tạo nhịp mà không cần quan tâm đến kết quả của test thuốc. Chỉ định chính cho test thuốc là ở các bệnh nhân có đặc điểm lâm sàng (c) và (d) - những bệnh nhân có tiền sử gia đình. Nếu test thuốc dương tính, điện sinh lý cơ tim cần được thực hiện.

Có 5 phương pháp thăm dò thường được sử dụng để hỗ trợ chẩn đoán:

- Kích thích bằng thuốc.

- Đo điện tâm đồ cải tiến với V1 - V3 đặt cao hơn.

- Holter 24h.

- Test gắng sức.

- Thăm dò điện sinh lý cơ tim.

\section{Nguy cơ của hội chứng Brugada}

Tất cả các biểu hiện lâm sàng của hội chứng Brugada đều liên quan đến các loạn nhịp thất 
nguy hiểm. Đột tử tim có thể là biểu hiện đầu tiên và xuất hiện ở một phần ba các trường hợp bệnh nhân có hội chứng Brugada. Các biến cố loạn nhịp thường xuất hiện giữa 22 - 65 tuổi và thường hơn vào ban đêm hơn ban ngày, trong lúc ngủ hơn là lúc thức. Đột tử ở các bệnh nhân Brugada thường không liên quan đến gắng sức. Điện tâm đồ lưu lại từ các máy khử rung (ICD) cho thấy rằng các nhát bóp sớm, tự phát thường xuất hiện, giống hệt nhau về hình dạng sẽ khởi phát rối loạn nhịp thất, đó chính là khởi đầu loạn nhịp. Trong một phân tích trên 200 bệnh nhân bị hội chứng Brugada có triệu chứng hoặc không triệu chứng, nam giới và tiền sử gia đình được xác định là các yếu tố nguy cơ cho đột tử tim tiếp sau. Tuy nhiên, không có đặc tính nào có độ đặc hiệu cao (chỉ là 26\% đối với nam giới và $65 \%$ đối với tiền sử gia đình).

\section{Liên quan đến gây mê hồi sức}

Cấy máy khử rung là phương pháp điều trị hiệu quả duy nhất. Phương pháp được khuyến cáo cho những bệnh nhân có triệu chứng hoặc có kiểu điện tâm đồ hội chứng Brugada type 1 . Nhiều báo cáo ca lâm sàng cho thấy bệnh nhân có hội chứng Brugada đã được gây mê thành công. Tuy nhiên, một số hướng dẫn nhất định phải tuân theo trước, trong và sau mổ để giảm thiểu tối đa nguy cơ xảy ra các biến cố tim mạch bất lợi. Tất cả bệnh nhân có hình ảnh điện tâm đồ type 1 , bất kể họ có được chẩn đoán xác định hội chứng Brugada hay không, nên được coi là có hội chứng này trong giai đoạn phẫu thuật.

Phương pháp gây mê thường được dung nạp tốt ở bệnh nhân có hội chứng Brugada. Tuy nhiên, do nguy cơ gây rối loạn nhịp tim ác tính tăng lên, cần phải thận trọng trong suốt thời gian phẫu thuật. Điều này cần kéo dài ít nhất 36 giờ sau khi phẫu thuật vì rối loạn nhịp tim có nhiều khả năng xảy ra trong giai đoạn hậu phẫu. Cần phải xem xét kỹ tiền sử bệnh nhân, đặc biệt là các triệu chứng lâm sàng, bệnh nhân đã được đặt máy khử rung chưa, các lần sốc đã được thực hiện, cường độ thế nào. Điện tâm đồ 12 đạo trình có thể giúp phân tầng rủi ro, mặc dù mô hình điện tâm đồ có thể khác nhau rất nhiều ở cùng một bệnh nhân.

Điện giải đồ của bệnh nhân phải được kiểm tra và hiệu chỉnh, cần đặc biệt quan tâm đến kali và canxi. Vì tăng kali máu, hạ kali máu và tăng canxi máu đều làm biến đổi hình dạng điện tâm đồ của hội chứng Brugada. Nồng độ Magiê máu cũng nên được giữ trong giới hạn bình thường. Bác sỹ gây mê cần trao đổi với bác sĩ tim mạch của bệnh nhân để tối ưu hoá việc điều trị và dự phòng loạn nhịp. Nếu bệnh nhân có máy khử rung (ICD), máy này nên được ngừng hoạt động vì có nguy cơ gây ra một cú sốc không phù hợp. Từ lúc ngừng ICD cho đến khi máy này được kích hoạt lại, nên theo dõi điện tâm đồ liên tục. Các phương tiện khử rung tim bên ngoài phải có sẵn, nếu có thể nên dán sẵn các miếng đệm lót khử rung. ${ }^{8}$

Tại thời điểm hội chẩn trước phẫu thuật, tất cả các thành viên trong ekip cần được biết về chẩn đoán sơ bộ, khả năng xuất hiện rối loạn nhịp tim ác tính và kế hoạch điều trị nếu loạn nhịp xảy ra. Phẫu thuật viên nên biết nguy cơ rối loạn nhịp tim với các thao tác cường phế vị (ví dụ: bơm hơi ổ bụng), nếu cần thì phải được thực hiện một cách thận trọng trong khi theo dõi điện tâm đồ. ${ }^{8}$

Nguy cơ rối loạn nhịp tim tăng lên khi mức độ chênh của ST tăng hơn, do đó cần phải cảnh giác với những thay đổi của các đạo trình trước tim bên phải trong tất cả các giai đoạn của cuộc mổ. Rất nhiều yếu tố làm chênh lên của đoạn ST ví dụ như tăng nhiệt độ, nên liên tục theo dõi nhiệt độ và duy trì đẳng nhiệt, tăng thân nhiệt phải được điều trị tích cực. Cần chuẩn bị sẵn sàng các thuốc chống loạn nhịp như isoprenaline, quinidine... (mặc dù thuốc những thuốc này chỉ dùng được qua đường tiêu hoá). ${ }^{9}$

Sự an toàn của các loại thuốc gây mê trong hội chứng Brugada đã được rút ra từ phân tích 
loạt trường hợp. Propofol đã được sử dụng an toàn trong hội chứng Brugada khi dùng liều bolus lúc khởi mê. Tuy nhiên, nhiều báo cáo về kiểu điện tâm đồ giống Brugada khi truyền propofol ở những bệnh nhân khỏe mạnh trước đó đã làm các bác sỹ gây mê lo ngại. Vì vậy, khi được sử dụng để duy trì gây mê hoặc an thần trong giai đoạn hậu phẫu, các rủi ro và lợi ích phải được cân nhắc cẩn thận. Tất cả các opioid đều có thể được sử dụng một cách an toàn, mặc dù dữ liệu về việc sử dụng Remfentanil còn hạn chế và nên cân nhắc khi sử dụng tramadol. Thuốc gây tê cục bộ cũng nên được sử dụng hết sức thận trọng. Khi được sử dụng, nên giảm liều lượng và tránh các khu vực hấp thu nhanh như gây tê thần kinh liên sườn. Nếu có thể, sử dụng lidocain phối hợp với adrenalin thay vì bupivacain vì khả năng hấp thu toàn thân ít hơn và có thời gian bán hủy ngắn hơn. Nên tránh dùng cocaine tại chỗ cho phẫu thuật mũi. ${ }^{9}$

Không có tác dụng phụ nào xảy ra khi sử dụng thuốc gây mê bay hơi, thuốc giãn cơ khử cực hoặc không khử cực, midazolam, paracetamol, thuốc chống viêm không steroid, hoặc thuốc chống nôn thông thường. Ephedrin, phenylephrin, atropin và glyco - pyrrolat đều được sử dụng mà không có biến chứng. Noradrenaline đã được báo cáo là làm tăng độ cao của đoạn ST. Neostigmine kết hợp với glycopyrrolate đã được sử dụng mà không có biến cố nào mặc dù các bác sỹ khuyến nghị rằng nên tiêm chậm, theo dõi điện tâm đồ liên tục vì khả năng tăng trương lực phế vị.

Tuy nhiên, nhiều tài liệu vẫn chưa thống nhất về việc sử dụng thuốc mê an toàn. Vì vậy, nhiều bác sỹ gây mê ủng hộ cách tiếp cận bệnh nhân một cách cá thể hoá. Nếu một bệnh nhân được xem là có nguy cơ cao bởi đã xuất hiện rối loạn nhịp tim từ trước, thì an toàn nhất là tránh sử dụng propofol, nên dùng midazolam và thuốc mê bốc hơi để khởi mê và duy trì mê.

\section{KÉT LUẬN}

Hội chứng Brugada là tình trạng gây ra do bất thường kênh natri ở tim, liên quan đến đột biến gen, có biểu hiện điện tâm đồ đặc trưng trên bệnh nhân cấu trúc quả tim bình thường. Bệnh nhân nguy cơ bị đột tử cao do rung thất hoặc nhịp nhanh thất mà không có triệu chứng báo trước. Nếu phải gây mê để phẫu thuật, bệnh nhân đối mặt với nguy cơ loạn nhịp nguy hiểm, các rối loạn nhịp có thể xuất hiện đến 36 giờ sau phẫu thuật. Rất nhiều yếu tố thuận lợi trước, trong hoặc sau phẫu thuật có thể khởi phát loạn nhịp. Để đảm bảo an toàn tối đa cho bệnh nhân, các bác sỹ gây mê cần chuẩn bị sẵn sàng máy khử rung, kiểm soát tối đa yếu tố nguy cơ nhất là các rối loạn điện giải, chỉ nên dùng Propofol để khởi mê, không truyền liên tục, thuốc mê bốc hơi tốt hơn khi dùng để duy trì mê. Thuốc giảm đau opioid, thuốc giãn cơ không ghi nhận bất thường khi sử dụng cho bệnh nhân có hội chứng Brugada.

\section{TÀI LIẸU THAM KHẢO}

1.ŞahinkayaHH,YaşarE, TekgülZT, Horsanalı BÖ, Özeroğlu E. Anaesthetic Management of a Patient with Brugada Syndrome. Turk $J$ Anaesthesiol Reanim. 2016;44(2):96 - 98. doi:10.5152/TJAR.2016.22230.

2. Brugada P, Brugada J. Right bundle branch block, persistent ST segment elevation and sudden cardiac death: a distinct clinical and electrocardiographic syndrome. A multicenter report. J Am Coll Cardiol. 1992;20(6):1391 1396. doi:10.1016/0735 - 1097(92)90253 - j.

3. Sieira J, Dendramis G, Brugada P. Pathogenesis and management of Brugada syndrome. Nat Rev Cardiol. 2016;13(12):744 - 756. doi:10.1038/nrcardio.2016.143.

4. Gupta PK, Hopkins PM. Stoelting's Anesthesia and Co - existing Disease. British 
Journal of Anaesthesia. 2018;120(2):416 - 417. doi:10.1016/j.bja.2017.12.005.

5. Levy D, Bigham C, Tomlinson D. Anaesthesia for patients with hereditary arrhythmias part I: Brugada syndrome. BJA Education. 2018; 18(6):159 - 165. doi:10.1016/j. bjae.2018.03.004.

6. Vohra J, Rajagopalan S, CSANZ Genetics Council Writing Group. Update on the Diagnosis and Management of Brugada Syndrome. Heart Lung Circ. 2015;24(12):1141 - 1148. doi:10.1016/j.hlc.2015.07.020.

7. Phạm Hữu Văn. Hội chứng Brudada và đột tử tim. Hội Nhịp tim học Thành phố Hồ Chí Minh. 2012; Bồi dưỡng - Đào tạo.

8. Postema PG, Neville J, de Jong JSSG, Romero K, Wilde AAM, Woosley RL. Safe drug use in long QT syndrome and Brugada syndrome: comparison of website statistics. Europace. 2013;15(7):1042 - 1049. doi:10.1093/ europace/eut018.

9. Kloesel B, Ackerman MJ, Sprung J, Narr BJ, Weingarten TN. Anesthetic management of patients with Brugada syndrome: a case series and literature review. Can $J$ Anaesth. 2011;58(9):824 - 836. doi:10.1007/s12630 - 011 - 9546 - y.

\section{Summary}

\section{ANESTHESIA FOR PATIENTS WITH BRUGADA SYNDROME}

Brugada syndrome is a condition associated with cardiac sodium channel abnormalities in a structurally normal of heart. Diagnosis of the disease is based on features on electrocardiogram plus clinical manifestations and/or genetic examination. Patients with Brugada syndrome can suddenly die from ventricular arrhythmias without predicted symptom, so if surgery is required, the risk is very high. Anesthesiologists need to understand the pathogenesis of the disease, the predisposing factors for the occurrence of arrhythmias, and the drugs that can trigger the arrhythmia. Thereby, it warrants to select the appropriate method of anesthesia and appropriate anesthetics to ensure maximum safety for this patient. Based on a review of a series of case reports plus literature review, the solution for this type of patients was to have an external defibrillator ready, control risk factors, maintain anesthesia with inhalational anesthetics, and not to administer infused propofol continuously.

Keywords: Brugada syndrome, ventricular arrhythmias, anesthesia for patients with arrhythmias 